\title{
CEMENT MATRIX CONTAINING MICRONIZED RECYCLED CONCRETE AND THE INFLUENCE OF ADDITIVES
}

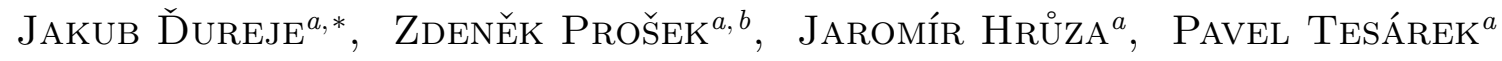 \\ ${ }^{a}$ CTU in Prague, Faculty of Civil Engineering, Thakurova 7, 166 29 Prague 6, Czech Republic \\ ${ }^{b}$ CTU in Prague, UCEEB, Trinecka 1024, 27343 Bustehrad, Czech Republic \\ * corresponding author: jakub.dureje@fsv.cvut.cz
}

\begin{abstract}
The article deals with the selection of a suitable additives in cement composite material for the production of a masonry block. The blocks contains recycled concrete which replacing $40 \%$ cement. The recyclate comes from concrete drainage gutters. Based on previous measurements, two hardening accelerators and one superplasticizer were selected. To determine the effect of these additives on the recycled cement composite, pairs of samples sets were produced, of which one set contains concrete recyclate and the other one does not contain it. The dynamic modulus of elasticity and the dynamic shear modulus were measured by the resonance method at the age of samples 1, 7, 14,21 and 28 days, and by an ultrasound method at 28 days of age. Then was measured compressive strength. All values were compared with the values measured on the reference samples.
\end{abstract}

KEYWORDS: Recycled concrete, micro-milled concrete, influence of additives, resonance method, dynamic modulus of elasticity, dynamic shear modulus.

\section{InTRODUCTION}

Concrete waste, which comes from demolition of buildings, can be recycled but there can be problem with different properties and inhomogeneity of this waste due to the presence of other materials (bricks, wood, glass, reinforcement, etc.). The quality of the recycled concrete depends on the care of sorting this old waste. Unfortunately, waste sorting is negatively reflected in the price of this raw material. Recycled concrete is most commonly used as the underlayer under the road. Usually is used fraction of recyclate greater than $1 \mathrm{~mm}$, the use of finer fractions brings many complications and additional financial costs [1, 2]. The article deals with the measurement of the dynamic modulus of elasticity and compressive strength of samples containing cement, various additives and concrete recyclate. Recycled concrete was used, including the finest $0-1 \mathrm{~mm}$ fractions, which were then finely grinded using a highspeed milling process. The use of this fine fraction, which has almost no use today, is an advantage of the material. These fine fractions of concrete recyclates are often stored in landfills, and their use can reduce the volume of stored waste materials which is also environmental friendly. Finely ground recycled concrete was used in cement composites as a filler with certain bonding properties. From previous experiments, it has been shown that with the increasing percentage of recyclate in the cementitious composite, compressive strength decreases [3, 4. In order to reach a certain compressive strength, various additives to concrete has been used which cause an increase the initial and final compressive strengths. The examined material is planned to be used for the production of concrete blocks for the construction of single-storey buildings in the Middle East. Concrete blocks could then be lightened to achieve thermal insulation properties and then used as a perimeter masonry.

\section{MATERIAls AND SPECIMENS}

A total of 8 sets of samples were produced, each set containing 6 specimens. The first half of the samples were produced with no recycled concrete in the second half was replaced $40 \%$ of cement by recycled concrete. The two sets were reference (with and without recyclate), the other sets contained additives. For the production of samples was used CEM I 42.5 R Portland cement - Radotin from Českomoravsk y cement. Recycled concrete comes from drainage gutter. A fraction $0 / 16 \mathrm{~mm}$ was used for high-speed milling process. The resulting grain size was $<0.25 \mathrm{~mm}$. The fineness of the ready-to-use recycled concrete approached the fineness of the cement with a surface area $361 \mathrm{~m}^{2}$. Based on previous measurements, suitable additives were selected. Superplasticizing additive (P3) based on modified polycarboxylates which is especially designed for concrete with requirements for high short and final compressive strengths. The accelerator (U1) which does not impair the workability of the fresh mixture, slightly reduces the amount of mixing water. It increases the initial and final strength of the concrete. The (U2) accelerator is composed of soluble mineral salts and organic compounds. Combination of this substances has effect which accelerating hardening of concrete (Table 1). The water ratio (weight of water divided by mass of cement and recyclate) $\mathrm{W} /(\mathrm{C}+\mathrm{R})$ was determined on the basis of the flow expansion test after 10 and 20 impulses to achieve approximately equal expansion of the fresh concrete 
mixture for all mixtures. The water ratio ranged from 0.21 to 0.31 , more mixed water was used for samples containing recycled concrete to achieve approximately the same workability (Table 2). Laboratory molds measuring approximately $40 \times 40 \times 160 \mathrm{~mm}$ were used to make samples. Test specimens were removed from the molds after 24 hours and stored under water in a laboratory environment at a temperature of $21 \pm 2{ }^{\circ} \mathrm{C}$ and a relative humidity of $50 \pm 5 \%$ for 28 days.

\section{EXPERIMENTAL METHODS}

For all samples, the dynamic modulus of elasticity at the age of $1,7,14,21$ and 28 days was continuously measured. A resonance method was used to measure the dynamic modulus of elasticity of samples. Advantage of this method is a speed of measurement and repeatability because it is non-destructive method. The method is based on the calculation of dynamic modulus of elasticity and dynamic shear modulus based on measured fundamental resonance frequencies of longitudinal, transverse (bending) and torsional oscillation. The resonance frequencies were measured in the laboratory using the Brüel \& Kjær measuring system, consisting of the Brüel \& Kjær type 4519-003 response sensor, the Brüel \& Kjær type 8206 impact hammer, the Brüel \& Kjær Fron-end 3560B-120 measuring center and the control notebook. The sample was placed on supports of sufficiently low stiffness so that the supports were placed at the nodal points of the first waveform corresponding to the given oscillation - longitudinal, transverse or rotational (Fig. 1). The response sensor $(\mathrm{S})$ was attached to the sample to the appropriate position and the oscillation was excited by the impact hammer (B). Both signals, response and excitation were recorded and converted to a frequency domain using a fast Fourier transform. Subsequently, the PULSE LabShop software version 14.0.1 has calculated the transmission function. Based on the resonance peaks in the transmission function, the fundamental resonance frequency of the given oscillation was determined. From the measured resonance frequency, weight, and sample dimensions, the dynamic modulus of elasticity and shear modulus were determined [5]. The dynamic modulus of elasticity was controlly measured by the ultrasonic pulse method at the age of 28 days. The method is based on the principle of measuring the velocity of ultrasound pulse in the material under investigation. Ultrasound pulse spreads through each material at a different speed, it depends on its composition and its properties. Implus is induced by an electroacoustic exciter attached on the surface of the sample to be tested. When the impulse passes through a path of known length (sample length), the vibration pulse is converted to an electrical signal by the sensor, and the electronic time circuit allows to measure the pulse passage time [6]. Measurement was carried out by attaching sensors to the opposite sides of the sample, and then measuring the time of ultrasound wave spreading through the length of the sample. The sonic Vita gel was used to achieve perfect contact between the specimen and the ultrasonic sensor. To calculate the dynamic modulus of elasticity by the ultrasonic method, the following equation was used:

$$
E_{u l t}=\rho \cdot \frac{L^{2}}{t^{2}} \cdot \frac{1}{k^{2}} \cdot 10^{-9}
$$

$E_{u l t}$ the modulus of elasticity measured by the ultrasonic method [GPa],

$\rho$ is the bulk density of the measured sample $\left[\mathrm{kg} \cdot \mathrm{m}^{-3}\right]$,

$L$ is the length of the measured sample $[\mathrm{m}], t$ is the time of ultrasound wave spreading through length of the sample [s], $k$ is the coefficient of the dimensionality [-].

Subsequent destructive tests were performed on the samples. Compressive strength was tested in an EV 40 hydraulic press with a maximum force of $400 \mathrm{kN}$ according to EN 12390-3 Testing of hardened concrete - Part 3: Compressive strength of specimens 77. The hydraulic press spread pressure over the area of the $40 \times 40 \mathrm{~mm}$ steel plates to the test sample until it was crushed. Load speed was $0.3 \mathrm{~mm} / \mathrm{s}$.

\section{Results And Discussions}

Dynamic modulus of elasticity of each set are mean from all of 6 samples in the set. Control measurements and weighing have been performed on samples before every measuring by resonance method. The evaluation was performed on the basis of measured frequencies from longitudinal oscillation (Figure 2). To verify the accuracy of the results, the values of the dynamic modulus of elasticity from the transverse oscillations, which are almost identical to the values of the longitudinal oscillation modules, are also evaluated, which confirms the accuracy of the measurement. From the results of the dynamic modulus $E_{d y n}$, it is clear that the maximum increase in $E_{d y n}$ is during the first 7 days. Between 7 and 28 days there are no significant changes to $E_{d y n}$. The highest values of $E_{d y n}$ reach samples with superplasticizer P3, in comparison with samples without recyclate (CP3 $23.0 \mathrm{GPa}$ ) and in comparison with samples with recyclate (CRP3 19.0 GPa). The difference between the CP3 and CRP3 sets is approximately $4.0 \mathrm{GPa}$. The drop in values of about $4 \mathrm{GPa}$ is noticeable for all pairs of ingredients with a given additive and without or with recycled concrete. We can declare that $40 \mathrm{wt}$. $\%$ of recycled material causes the dynamic elastic modulus to drop by about $4 \mathrm{GPa}$ in 28 days due to less matrix coherence. Unsatisfactory values reached samples with hardening accelerators (CU1, CU2, CRU1, CRU2) whose $E_{d y n}$ values are only slightly higher or even lower than the $E_{d y n}$ reference sets $(\mathrm{C}, \mathrm{CR})$. This additives cause initial increases in strength, therefore at the age of 7 days, the samples with recycled material reached higher values than the reference mixture. However, a subsequent slower increase in the modulus 


\begin{tabular}{clccc}
\hline Designation & Product based on & $\begin{array}{c}\text { Normal dosing } \\
{[\text { wt. \% of cement }]}\end{array}$ & $\begin{array}{c}\text { Density } \\
{\left[\mathrm{kg} / \mathrm{m}^{3}\right]}\end{array}$ & $\begin{array}{c}\mathrm{pH} \\
{[-]}\end{array}$ \\
\hline P3 & Modified polycarboxylates & 1.0 & $1060 \pm 10$ & $6.5 \pm 2.0$ \\
U1 & Unchlorinated liquid & $1.0-3.0$ & $1450 \pm 30$ & $7.5 \pm 2.0$ \\
U2 & Soluble mineral salts and & 1.5 & $1300 \pm 10$ & $9.5 \pm 1.0$ \\
& organic substances & & & \\
\hline
\end{tabular}

TABLE 1. Selected additives and its properties.

\begin{tabular}{ccccc}
\hline Set/ Material & $\begin{array}{c}\text { Cement } \\
{[\mathrm{g}]}\end{array}$ & $\begin{array}{c}\text { Micronized } \\
\text { concrete recyclate } \\
{[\mathrm{g}]}\end{array}$ & $\begin{array}{c}\text { Water ratio } \\
{[-]}\end{array}$ & $\begin{array}{c}\text { Additive } \\
{[\text { wt. \% of cem. + recycl.] }}\end{array}$ \\
\hline C & 1000 & 0 & 0.29 & 0.0 \\
CP3 & 1000 & 0 & 0.21 & 1.0 \\
CU1 & 1000 & 0 & 0.29 & 1.5 \\
CU2 & 1000 & 0 & 0.29 & 1.5 \\
CR & 600 & 400 & 0.31 & 0.0 \\
CRP3 & 600 & 400 & 0.25 & 1.0 \\
CRU1 & 600 & 400 & 0.30 & 1.5 \\
CRU2 & 600 & 400 & 0.30 & 1.5 \\
\hline
\end{tabular}

TABLE 2. Composition of the samples.

of elasticity of mixtures with hardening accelerators resulted in some cases (CU1, CRU1) that modulus not reaching the value of reference $(\mathrm{C}, \mathrm{CR})$. The dynamic shear modulus is also affected by replacing cement with recycled concrete. In each of the two groups (with and without recyclate), samples with the superplasticizer P3 reached highest values of the $G_{d y n}$ (CP3 - 9.3 GPa, CRP3 - 7.7 GPa). Provable jump for all mixtures (Figure 3) can be seen between the first day and 7 days of age when strength raises fastest in the all samples. With increasing time from 7 days onwards, the shear modulus increase is only gradual, practically negligible. Negative effects on the dynamic shear module are mainly U1 and U2 solidification accelerators, especially for fine-grained recycled concrete mixtures (CRU1, CRU2), which achieve lower elastic moduli than reference samples. The compressive strength test was also carried out in the age of 28 days. For this test were used halfs of the beams from previous bending tests. Total of 11 samples (half beams) were tested from each set. The resulting values are therefore an arithmetic mean of 11 values. The results of the test show higher values of compressive strength for mixtures without recycled concrete versus mixtures with recyclate. The greatest difference in strength between samples with and without recycled concrete is in the pair of mixtures with accelerators U1 and U2. Significant reductions in the strength of CRU1 and CRU2 samples may be due to the adverse effects of accelerators on recycled concrete (Figure 4 ).

\section{Conclusion}

The article deals with the selection of the most suitable additive for the production of concrete blocks containing micronized concrete recyclate. Based on previous measurements, two solidification accelerators (U1 and U2) and one superplasticizer (P3) were selected [8, 9]. For comparison and identification of the influence of recycled concrete, pairs of sample sets were produced, which differed only by replacing part of the cement with micronized recycled concrete. Based on results, it can be concluded that:

- The highest increase in the dynamic modulus of elasticity of mixtures occurs in the first 7 days of hardening. Most then within 24 hours.

- 40 wt. $\%$ of recycled concrete will cause a dynamic elastic modulus drop in 28 days for all 24 samples with recycled concrete of about $4 \mathrm{GPa}$.

- Adding accelerators to the mixture cause slight increase of water ratio.

- CRP3 has proven to be the best in compression strength tests. It is the strongest tested composite with recyclate.

- The U1 accelerator proved to be totally inappropriate, the value of the dynamic modulus $E_{d y n}$ is even lower than reference.

- The proposed modified CRP3 mixture can be used to make lightweight concrete blocks, which can be used to masonry the perimeter walls of the singlestorey building.

- The proposed modified resultant matrix (CRP3 

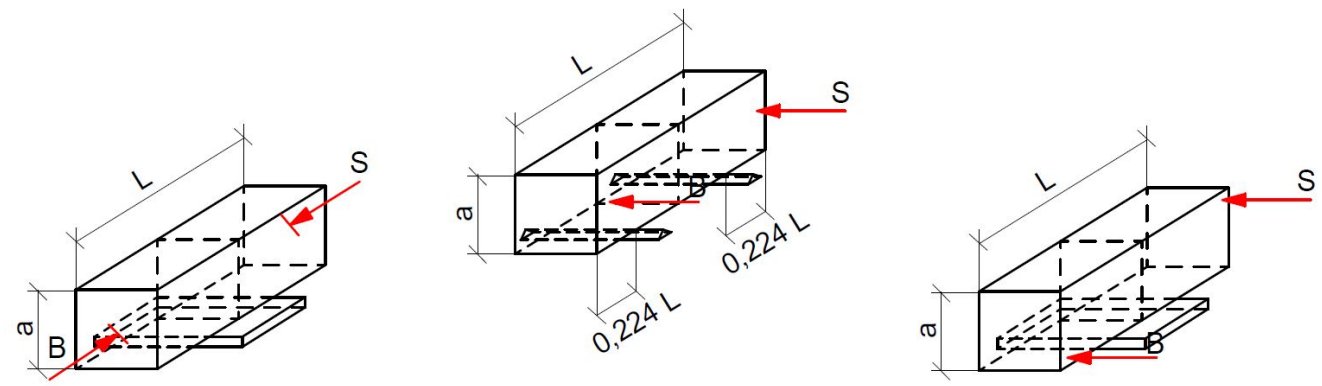

FiguRE 1. Measurement basic natural frequencies from longitudinal (left), transverse (center), and torsional (right) oscillations.

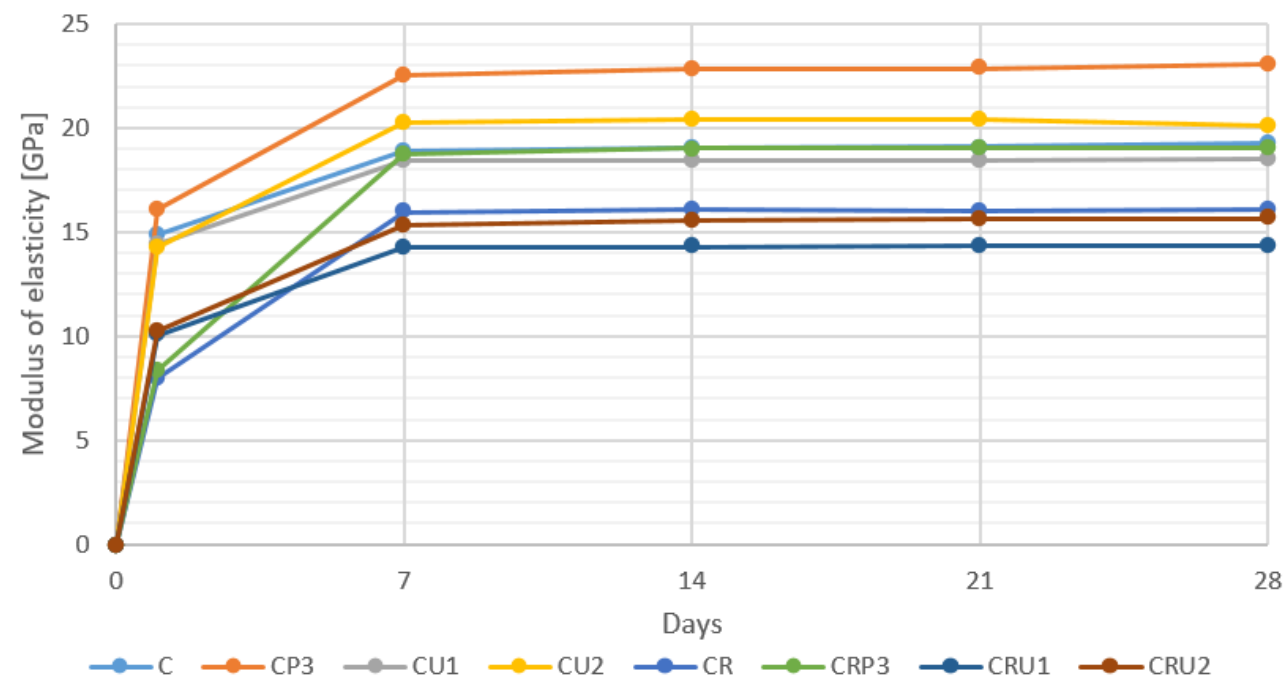

FIGURE 2. Increase the dynamic modulus of elasticity over time.

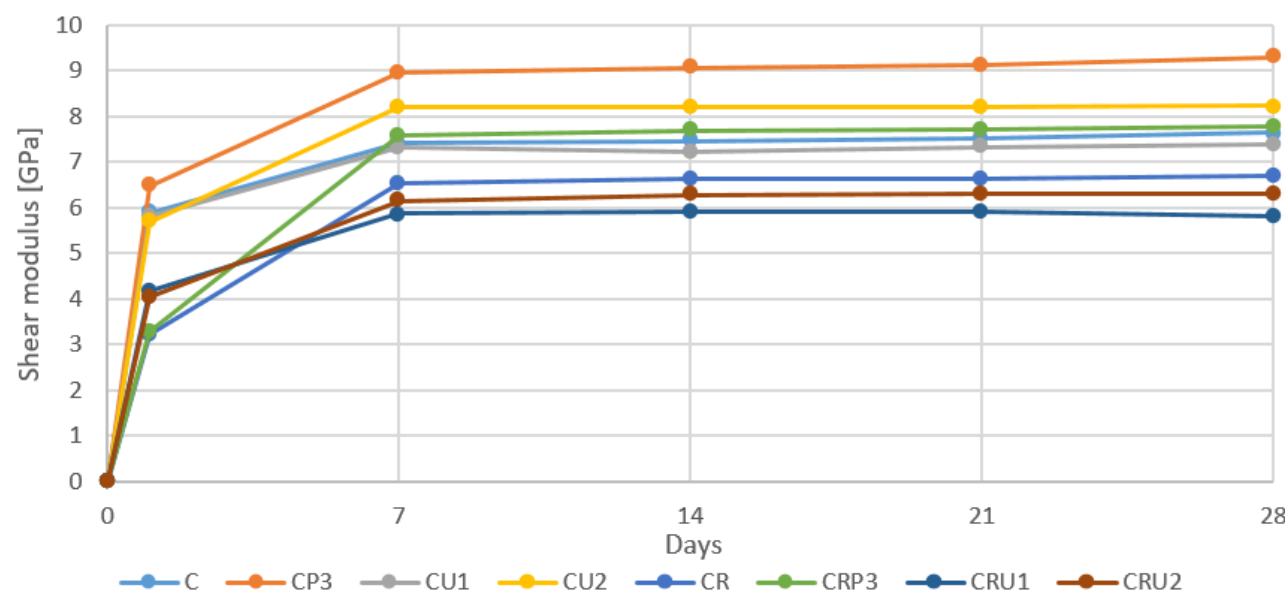

FiguRE 3. Increase the dynamic shear modulus over time.

mixture) can be lightened because of sufficient compressive strength, eg. by foaming.

\section{LIST OF SYMBOLS}

$E_{u l t}$ Modulus of elasticity measured by the ultrasonic method [GPa]

$\rho \quad$ Bulk density of the measured sample $\left[\mathrm{kg} \mathrm{m}^{-3}\right]$
$L \quad$ Length of the measured sample $[\mathrm{m}]$

$t$ Time of ultrasound wave spreading through length of the sample $[\mathrm{s}]$

Re Coefficient of the dimensionality 


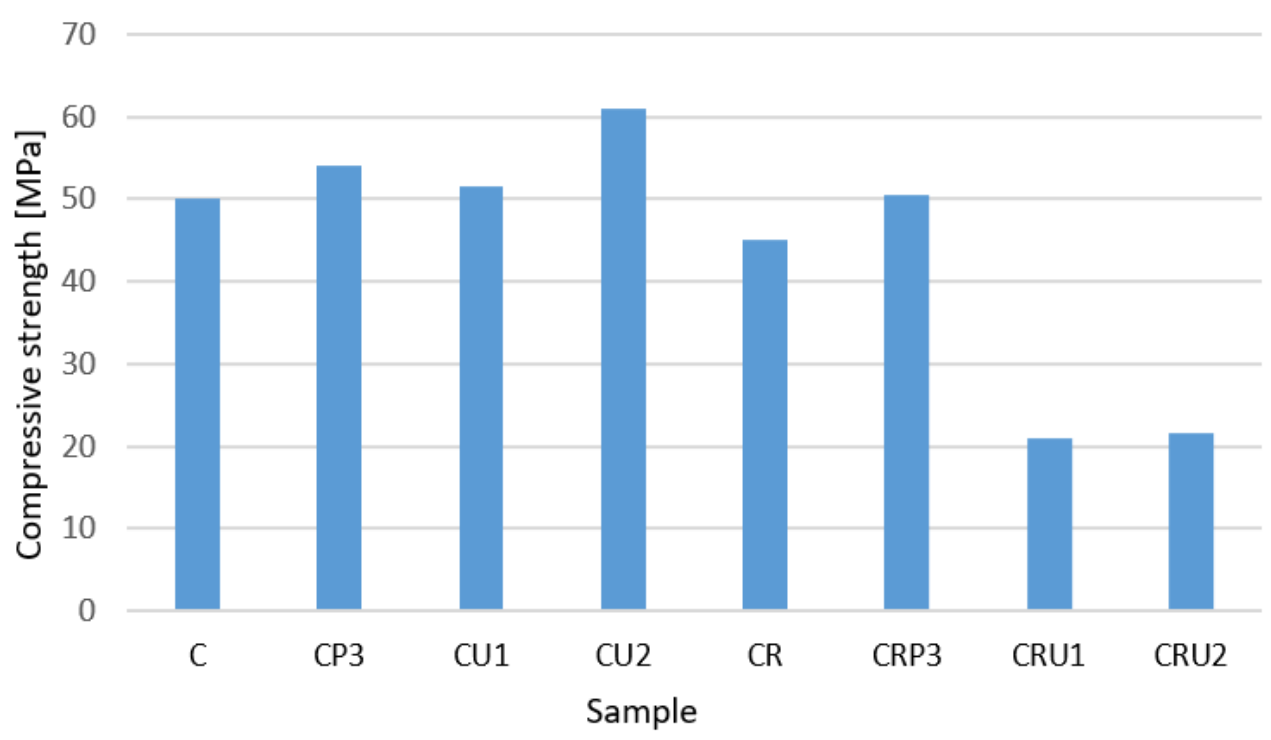

Figure 4. Compressive strength.

\section{ACKNOWLEDGEMENTS}

This outcome was supported by the Czech Technical University in Prague under No. SGS16/201/OHK1/3T/11, by the Czech Science Foundation research projects GACR 17-06771S and by the Ministry of Education, Youth and Sports within National Sustainability Programme I, project No. LO1605. The authors also thank the Center for Nanotechnology in Civil Engineering at the Faculty of Civil Engineering, the Joint Laboratory of Polymer Nanofiber Technologies of the Institute of Physics, Academy of Science of Czech Republic, and the Faculty of Civil Engineering, Czech Technical University in Prague.

\section{REFERENCES}

[1] A. Barbudo, F. Agrela, J. Ayuso, et al. Statistical analysis of recycled aggregates derived from different sources for sub-base applications. Construction and Building Materials 28(1):129-138, 2012.

[2] I. Vegas, J. A. Ibáñez, A. Lisbona, et al. Pre-normative research on the use of mixed recycled aggregates in unbound road sections. Construction and Building Materials 25(5):2674-2682, 2011.

[3] J. Topič, Z. Prošek, T. Plachý. Influence of increasing amount of recycled concrete powder on mechanical properties of cement paste. In IOP Conference Series: Materials Science and Engineering, vol. 236, p. 012094. IOP Publishing, 2017.
[4] J. Hrůza. Design of masonry elements with use of recycled concrete, 2016.

[5] ČSN 731372 Nedestruktivní zkoušení betonu-Rezonačnni metoda zkoušeni betonu, 2012.

[6] P. Dvorský. Diplomová práce využití ultrazvukové impulsové metody - nástroj pro stanovení pevnosti cementů 2012.

[7] ČSN, EN 12390-3-Zkoušení ztvrdlého betonu-Část 3: Pevnost v tlaku zkušebních těles, 2009.

[8] E. Anastasiou, K. G. Filikas, M. Stefanidou. Utilization of fine recycled aggregates in concrete with fly ash and steel slag. Construction and Building Materials 50:154-161, 2014.

[9] F. Cartuxo, J. De Brito, L. Evangelista, et al. Rheological behaviour of concrete made with fine recycled concrete aggregates-influence of the superplasticizer. Construction and Building Materials 89:36-47, 2015. 